As-Syifaa Vol 09 (02) : Hal. 201-210, Desember 2017

ISSN : 2085-4714

\title{
ISOLASI DAN IDENTIFIKASI GOLONGAN KOMPONEN KIMIA AKTIF ANTIBAKTERI EKSTRAK N-BUTANOL SAWO MANILA (Achras zapota LINN.) ASAL KOTA PALOPO
}

\author{
Rusli, Dedy Prayitno
}

\author{
Fakultas Farmasi Universitas Muslim Indonesia, Makassar \\ Email : rusli@umi.ac.id
}

\begin{abstract}
Sawo manila is one of the Zapotaceae family plant which have been investigated on n-butanol extract generate active spot as an antibacterial, therefore isolation and investigation of which is necessary. The aim of the investigation was to identify the chemical group of antibacterial active chemically. The methanol extract obtained by maceration method was 50 gram, continued by partition with diethyl eter obtained 17,3 gram dried extract, the residue ofiz then partition with n-butanol obtained 3,7 gram dried extract the extract of which isolated by conventional colomn cromotography method obtained 7 fractions. The second fraction on Bioautografi$T L C$ given antibacterial activity. Then the fraction re-isollated by preparative-TLC gained the second (2nd) band of which crystalzed by two dimention of TLC and multi eluen system. The single spot had positive reaction on the spot visualizer was alkaloid group with the maximum wavelength on 295,5 $\mathrm{nm}$ and the infra red spectra interpretation shown that amin group (NH) on wave value $1247 \mathrm{~cm}^{-1}, 2361 \mathrm{~cm}^{-1}$, and $1294 \mathrm{~cm}^{-1}$ strengthen by secondary amin functional group (-NH-), within wave value $3447 \mathrm{~cm}^{-1}$ and 1294,26 $\mathrm{cm}^{-1}$, aromatic $\mathrm{CH}$ group and the aromatic amin $1451 \mathrm{~cm}^{-1}$, unconjugated alkene group on $1652.32 \mathrm{~cm}^{-1}$ strengthen by alkene group on 2922,37 $\mathrm{cm}^{-1}$.
\end{abstract}

Key words : Antibakterial, Sawo Manila, Achras zapota Linn.

\section{PENDAHULUAN}

Salah satu tumbuhan yang sering digunakan sebagai obat tradisional oleh masyarakat adalah sawo manila (Achras zapota Linn), suku Zapotaceae sebagai obat tifus, gangguan pencernaan (diare), batu ginjal dan malaria. Selain itu Herminia de Guzman Ladion, seorang pakar kesehatan di Filipina, memasukkan sawo sebagai salah satu tanaman obat, untuk mengobati sakit diare dan gusi bengkak atau peradangan mulut. Getah buah dan daun sawo berkhasiat juga sebagai obat mencret, disamping itu getahnya dapat juga digunakan untuk campuran gula-gula pada pembuatan permen. Buah sawo manila muda berkhasiat adstrigensia dan mempunyai kegunaan sebagai 
Isolasi dan identifikasi golongan komponen kimia aktif antibakteri ekstrak n-butanol sawo manila (Achras zapota LINN.) asal kota Palopo

obat diare (mencret), disentri dan kencing batu. ${ }^{1,2,3}$

Buah sawo manila muda mengandung tanin, zat besi dan mengandung getah $0,8 \%$, sedangkan pada buah yang matang mengandung gula, zat asam, kalori, serabut, kalium, karoten, natrium, protein, lemak, karbohidrat, kalsium, fosfor, zat besi, vitamin $A$, vitamin B1, vitamin B3, vitamin $C$ dan air. Pada daun mengandung flavanoid dan saponin dan pada kulit kayu yang masih muda mengandung alkaloid, tanin dan saponin. ${ }^{1,2,3,4}$ Kandungan kimia yang telah diketahui dalam klika sawo manila mengandung alkaloid dan tanin, sedang pada buah muda mengandung tanin, flavanoid, asam dan besi. ${ }^{2,4}$

Hasil penelitian menunjukan bahwa pada ekstrak n-butanol menunjukan aktivitas antibakteri terhadap bakteri Escherichia coli dan Salmonella typhi secara KLTBioautografi. Hal inilah yang mendasari penelitian ini untuk mengisolasi dan mengidentifikasi golongan senyawa yang aktif.

Tujuan penelitian adalah untuk mengetahui golongan komponen kimia aktif antibakteri isolat dari ekstrak n-butanol yang terdapat pada daun sawo manila (Achras zapota Linn.).

\section{METODOLOGI PENELITIAN}

\section{Alat-alat dan bahan}

Alat-alat yang digunakan adalah botol penyemprot penampak bercak, chamber (Camag), Lampu UV 254 nm dan $366 \mathrm{~nm}$ (Philips), , sentrifuge, seperangkat alat rotavapor (Ika Werke Ika (B) Rvor), seperangkat alat maserasi,, seperangkat alat kromatografi kolom, seperangkat alat KLT preparatif,, Spektroskopi IR (Shimadzu) dan Spektroskopi UV (Shimadzu). Bahan-bahan yang digunakan seperti air suling, benzen (teknis), daun sawo manila (Achras zapota Linn.), dietil eter (teknis), etanol 96\% (teknis), kloroform (teknis), lempeng $K L T$, lempeng KLT preparatif, metanol (teknis), n-heksan (teknis), nbutanol (tekhnis), penampak bercak asam sulfat $10 \%$, asam perklorat, Dragendorf, vanilin-asam sulfat, Lieberman-Burchard, Mayer,, yodium KI, Silika Gel G 60 F 254 (Merck).

\section{Prosedur penelitian}

\section{Ekstraksi Dengan Pelarut Dietil Eter dan n-Butanol ${ }^{5,6}$}

Sebanyak 30 gram ekstrak metanol kering diambil dan dilakukan partisi padat cair dengan menggunakan dietil eter sebanyak 50 $\mathrm{ml}$, hasil partisi disentrifuge, disaring, 
Isolasi dan identifikasi golongan komponen kimia aktif antibakteri ekstrak n-butanol sawo manila (Achras zapota LINN.) asal kota Palopo

dipisahkan antara filtrat (dietil eter) dan residu dipartisi kembali hingga filtrat dietil eter tidak berwarna sebanyak 12 kali, lalu diuapkan dan didapatkan ekstrak dietil eter kering sebanyak 17,5 gram. Residu dari partisi dietil eter dilanjutkan partisi padat cair dengan n-butanol sebanyak $50 \mathrm{ml}$, hasil partisi disentrifuge, disaring, dipisahkan antara filtrat (n-butanol) dan residu dipartisi kembali hingga filtrat n-butanol tidak berwarna sebanyak 8 kali. Hasil ekstraksi nbutanol yang diperoleh kemudian diuapkan hingga diperoleh ekstrak nbutanol kering 3,7 gram.

\section{Isolasi Sampel Dengan Kromatografi Kolom 7,8,9}

Ekstrak n-butanol kering daun sawo manila (Achras zapota Linn.) sebanyak 3 gram dengan metode kering dimasukkan ke dalam kolom, diratakan dan dimampatkan. Cairan pengelusi yang kepolarannya paling rendah yaitu n-heksan:kloroform (50:0) $100 \mathrm{~mL}$ ditambahkan melalui dinding kolom, dilanjutkan dengan cairan penyari yang kepolarannya lebih tinggi, berturut-turut yaitu nhexsan:kloroform (15:1), (10:1), (5:1), $(2,5: 1), \quad(1: 1), \quad(1: 2,5), \quad(1: 5), \quad(1: 10)$, (1:15), (0:50), kloroform:metanol (1:1) dan terakhir adalah metanol $100 \mathrm{~mL}$. Eluen yang keluar ditampung sebagai fraksi dengan volume $25 \mathrm{ml}$. Fraksi yang memberikan profil kromatogram yang sama pada identifikasi dengan kromatografi lapis tipis disatukan dalam satu fraksi. Hasil kromatografi kolom cair didapat 7 fraksi.

Isolasi Sampel Dengan Kromatografi Lapis Tipis Preparatif Dari hasil uji aktivitas antimikroba terhadap Eschesrichia coli secara KLT-Bioaotografi menunjukkan fraksi II yang memberikan aktivitas antimikroba, maka diisolasi fraksi II dengan menggunakan Kromatografi Lapis Tipis Preparatif. Penyiapan KLT preparatif. Fraksi II dari hasil kromatografi kolom cair ditotolkan pada garis penotolan Kromatografi Lapis Tipis Preparatif, dikeringkan kemudian dielusi dengan menggunakan kloroform:n-heksan (10:1) dan didapat 4 fraksi.

\section{Pemurnian Kristal}

Fraksi IIC pada Kromatografi Lapis Tipis Preparatif adalah fraksi yang menunjukkan adanya aktivitas antimikroba pada Escherichia coli. Pada fraksi IIC dilakukan pemurnian. Pengujian pemurnian dilakukan dengan kromatografi lapis tipis dua dimensi dan elusi dengan sistem multi eluen. 
Isolasi dan identifikasi golongan komponen kimia aktif antibakteri ekstrak n-butanol sawo manila (Achras zapota LINN.) asal kota Palopo

Kromatografi Lapis Tipis Dua Dimensi

Kristal murni yang telah didapat kemudian ditotol pada lempeng KLT dengan ukuran $20 \times 20 \mathrm{~cm}$. Lalu dielusi dengan menggunakan dua cairan pengelusi, cairan pengelusi yang pertama menggunakan eluen benzen : etil asetat $(5: 1)$, dan cairan pengelusi yang kedua adalah kloroform : n-heksan (10:1). Apabila pada dua kali proses elusi ini hanya menunjukkan satu bercak tunggal maka dapat dikatakan bahwa kristal yang didapatkan adalah komponen kimia yang tunggal.

\section{Elusi sistem Multi Eluen ${ }^{10}$}

Uji kemurnian kristal juga dilakukan dengan menggunakan beberapa variasi eluen yaitu kloroform : n-heksan (10:1), benzen : etanol (5:1) dan etil asetat : etanol (5:1). Penampakan bercak tunggal menandakan bahwa golongan senyawa dari kristal yang didapat merupakan golongan komponen kimia yang tunggal.

\section{Identifikasi Sampel}

\section{Identifikasi Penampak Bercak}

Kristal murni yang didapat kemudian ditotolkan pada lempeng KLT dan dielusi. Hasil pengelusian kemudian disemprotkan penampak bercak golongan komponen kimia.
Penampak bercak yang digunakan adalah Dragendorf, Mayer, JKJ (golongan alkaloid), vanilin-asam sulfat (golongan steroid), LiebermanBurchard (golongan steroid), asam perklorat (golongan steroid). Hasil penyemprotan dipanaskan pada oven pada suhu $120^{\circ} \mathrm{C}$ selama beberapa saat untuk mendapatkan intensitas warna yang maksimum pada bercak.

\section{Identifikasi Spektrofotometri Ultra Violet-Visibel}

Kristal murni yang diperoleh dari fraksi IIC di identifikasi dengan spektrofotometer ultra violet. Senyawa dilarutkan dalam kloroform kemudian cuplikan ditempatkan di antara monokromator dan detektor. Spektrum yang dihasilkan direkam pada alat pencatat.

\section{Identifikasi Spektrofotometri Infra Merah ${ }^{10}$}

Kristal murni yang diperoleh dari fraksi IIC dilanjutkan dengan identifikasi spektrofotometri infra merah dengan cara menempatkan cuplikan sebagai film yang tipis diantara dua lapisan natrium klorida yang transparan, kemudian ditempatkan pada celah sinar infra merah antara monokromator dengan detektor, selanjutnya direkam pada alat pencatat.

\section{Pengujian Secara KLT-Bioautografi}


Isolasi dan identifikasi golongan komponen kimia aktif antibakteri ekstrak n-butanol sawo manila (Achras zapota LINN.) asal kota Palopo

Hasil identifikasi KLT dari fraksi IIC pada KLT Preparatif dengan eluen Kloroform:n-heksan (10:1) dilanjutkan dengan Uji KLT-Bioautografi kontak dengan cara media GNA steril sebanyak $10 \mathrm{ml}$ dituang ke dalam cawan petri steril, lempeng KLT yang telah dielusi dengan eluen yang cocok diletakkan di atas permukaan medium agar yang telah diinokulasi dengan bakteri Escherichia colii dan dibiarkan selama 60 menit setelah itu lempeng tersebut diangkat dan dikeluarkan. Selanjutnya media diinkubasi pada suhu $37^{\circ}$ C selama \pm 24 jam. ${ }^{7,8}$

\section{HASIL PENELITIAN}

Tabel 1. Hasil Ekstraksi Daun Sawo Manila (Achras zapota Linn.)

\begin{tabular}{clc}
\hline No. & \multicolumn{1}{c}{ Sampel } & Bobot (gram) \\
\hline 1. & Ekstrak metanol & 30,0 \\
2. & Ekstrak Eter & 17,3 \\
3. & Ekstrak n-butanol & 3,7 \\
\hline
\end{tabular}

Tabel 2. Tabel Nilai Rf dan Warna Bercak pada Profil Kromatogram Ekstrak nButanol Daun Sawo Manila (Achras zapota Linn.).

\begin{tabular}{ccccccc}
\hline \multirow{2}{*}{ Bercak } & \multicolumn{3}{c}{ Nilai Rf } & \multicolumn{3}{c}{ Warna Bercak } \\
\cline { 2 - 7 } & UV 254 $_{\mathrm{nm}}$ & UV $\mathbf{3 6 6}_{\mathbf{n m}}$ & $\mathbf{H}_{\mathbf{2}} \mathbf{S O}_{\mathbf{4}} \mathbf{1 0} \%$ & $\mathbf{U V ~ 2 5 4}_{\mathrm{nm}}$ & $\mathbf{U V ~ 3 6 6}_{\mathbf{n m}}$ & $\mathbf{H}_{\mathbf{2}} \mathbf{S O}_{\mathbf{4}} \mathbf{1 0} \%$ \\
\hline 1 & 0.12 & 0.12 & 0.15 & $\mathrm{Hijau}$ & Ungu & Kecoklatan \\
2 & 0.31 & 0,32 & 0,31 & $\mathrm{Hijau}$ & Ungu & Ungu \\
3 & 0.65 & 0.65 & 0,65 & Hijau & Ungu & Ungu \\
\hline
\end{tabular}

Tabel 3. Tabel Nilai Rf dan Warna Bercak Pada Kromatogram Fraksi-Fraksi Hasil Isolasi Kromatografi Kolom Ekstrak n-Butanol Daun Sawo Manila (Achras zapota Linn.)

\begin{tabular}{|c|c|c|c|c|c|c|c|}
\hline \multirow[b]{2}{*}{ Fraksi } & \multirow[b]{2}{*}{ Bercak } & \multicolumn{3}{|c|}{ Nilai Rf } & \multicolumn{3}{|c|}{ Warna Bercak } \\
\hline & & UV $254_{n m}$ & UV $366_{n m}$ & $\mathrm{H}_{2} \mathrm{SO}_{4} 10 \%$ & UV $254_{n m}$ & UV $366_{n m}$ & $\begin{array}{c}\mathrm{H}_{2} \mathrm{SO}_{4} \\
10 \%\end{array}$ \\
\hline \multirow{2}{*}{ I } & 1 & - & 0,80 & 0,86 & - & Ungu & Cokelat \\
\hline & 2 & - & - & 0,78 & - & - & Cokelat \\
\hline \multirow{4}{*}{ II } & 1 & - & 0,76 & 0,86 & - & Ungu & Cokelat \\
\hline & 2 & - & - & 0,78 & - & - & Cokelat \\
\hline & 3 & - & - & 0,36 & - & - & Cokelat \\
\hline & 4 & - & - & 0,13 & - & - & Cokelat \\
\hline \multirow{4}{*}{ III } & 1 & 0,23 & 0,74 & 0,82 & Hijau & $\begin{array}{c}\text { Ungu } \\
\text { flouresensi }\end{array}$ & Cokelat \\
\hline & 2 & 0,05 & 0,32 & 0,14 & Ungu & $\begin{array}{l}\text { Ungu } \\
\text { flouresensi }\end{array}$ & Hijau \\
\hline & 3 & - & 0,24 & - & - & Ungu & - \\
\hline & 4 & - & 0,06 & - & - & Ungu & - \\
\hline
\end{tabular}


Isolasi dan identifikasi golongan komponen kimia aktif antibakteri ekstrak n-butanol sawo manila (Achras zapota LINN.) asal kota Palopo

\begin{tabular}{|c|c|c|c|c|c|c|c|}
\hline \multirow{4}{*}{ IV } & 1 & 0,22 & 0,72 & 0,82 & Hijau & Ungu & Cokelat \\
\hline & 2 & 0,05 & 0,30 & 0,16 & Hijau & $\begin{array}{l}\text { Ungu } \\
\text { flouresensi }\end{array}$ & Hijau \\
\hline & 3 & - & 0,26 & - & - & Ungu & - \\
\hline & 4 & - & 0,06 & - & - & Ungu & - \\
\hline \multirow{2}{*}{$\mathrm{V}$} & 1 & 0,12 & 0,31 & 0,82 & Hijau & $\begin{array}{c}\text { Ungu } \\
\text { flouresensi }\end{array}$ & Cokelat \\
\hline & 2 & - & 0,1 & 0,1 & - & Biru & Hijau \\
\hline \multirow[t]{2}{*}{ VI } & I & 0,1 & 0,30 & 0,06 & Hijau & $\begin{array}{c}\text { Ungu } \\
\text { flouresensi }\end{array}$ & Cokelat \\
\hline & II & - & 0,08 & - & - & Biru & - \\
\hline VII & - & - & 0,33 & - & - & $\begin{array}{c}\text { Ungu } \\
\text { flouresensi }\end{array}$ & - \\
\hline
\end{tabular}

Tabel 4. Nilai Rf Kromatogram Fraksi Hasil Isolasi KLT Preparatif Ekstrak n-Butanol Daun Sawo Manila (Achras zapota Linn.) dari Fraksi II pada Kromatografi Kolom.

\begin{tabular}{cccccc}
\hline \multirow{2}{*}{ Fraksi } & \multirow{2}{*}{ Pita } & \multicolumn{2}{c}{ Nilai Rf } & \multicolumn{2}{c}{ Warna Bercak } \\
\cline { 3 - 6 } & & UV 254 $_{\mathbf{n m}}$ & UV 366 $_{\mathbf{n m}}$ & $\mathbf{U V ~ 2 5 4}_{\mathrm{nm}}$ & UV 366 $_{\mathbf{n m}}$ \\
\hline \multirow{3}{*}{ II } & A & 0,81 & 0,83 & Hijau-biru & Cokelat \\
& B & 0,76 & 0,75 & Hijau & Cokelat \\
& C & 0,47 & 0,47 & Hijau & Cokelat Flouresensi \\
& D & 0,41 & 0,40 & Hijau & Cokelat Flouresensi \\
\hline
\end{tabular}

Tabel 5. Tabel Nilai Rf dan Warna Bercak pada Kromatogram Kristal Fraksi IIC Menggunakan Variasi Eluen (Multi Eluen).

\begin{tabular}{|c|c|c|c|c|c|c|}
\hline \multirow{2}{*}{ Bercak } & \multicolumn{3}{|c|}{ Nilai Rf } & \multicolumn{3}{|c|}{ Warna Bercak } \\
\hline & UV $254_{\mathrm{nm}}$ & UV $366_{\mathrm{nm}}$ & $\begin{array}{c}\mathrm{H}_{2} \mathrm{SO}_{4} \\
10 \% \\
\end{array}$ & $\begin{array}{c}\text { UV } \\
254_{\mathrm{nm}}\end{array}$ & UV $366_{\mathrm{nm}}$ & $\mathrm{H}_{2} \mathrm{SO}_{4} 10 \%$ \\
\hline I & 0,71 & 0,71 & 0,71 & Hijau & Ungu & Kuning -kecoklatan \\
\hline II & 0,52 & 0,52 & 0,52 & Hijau & Ungu & Kuning-kecoklatan \\
\hline III & 0,68 & 0,68 & 0,68 & Hijau & Ungu & Kuning-kecoklatan \\
\hline
\end{tabular}

Tabel 6. Tabel nilai Rf dan Warna Bercak Pada Kromatogram Kristal Fraksi II Dengan Metode Dua Dimensi

\begin{tabular}{ccccc}
\hline \multirow{2}{*}{ Sampel } & \multicolumn{2}{c}{ Nilai Rf } & \multicolumn{2}{c}{ Warna Bercak } \\
\cline { 2 - 5 } & UV 254 & UV 366 & UV 254 & UV \\
& 0,34 & 0,34 & Hijau & Ungu \\
\hline Arah I & 0,53 & 0,53 & Hijau & Ungu \\
Arah II & \multicolumn{2}{c}{}
\end{tabular}


Isolasi dan identifikasi golongan komponen kimia aktif antibakteri ekstrak n-butanol sawo manila (Achras zapota LINN.) asal kota Palopo

Tabel 7.Tabel Nilai Rf dan Warna Bercak Pada Kromatogram Kristal Fraksi IIC Hasil Identifikasi Dengan Penampak Bercak.

\begin{tabular}{ccccc}
\hline Sampel & Identifikasi Reagen & Jumlah Bercak & Rf & Warna Bercak \\
\hline 1 & Dragendorf & 1 & 0.53 & Orange \\
2 & Mayer & 1 & 0.53 & Kecoklatan \\
3 & JKJ & 1 & 0.53 & Coklat \\
\hline
\end{tabular}

Interprestasi data spektrum ultraviolet menunjukkan panjang gelombang maksimum 295,5 nm dan interprestasi data spektrum infra merah menunjukkan gugus amin $(-\mathrm{N}=)$ pada bilangan gelombang $1247 \mathrm{~cm}^{-1}$, $2361 \mathrm{~cm}^{-1}$ dan $1294 \mathrm{~cm}^{-1}$ diperkuat gugus amin sekunder (-NH-) pada bilangan gelombang $3447 \mathrm{~cm}^{-1}$ dan $1294,26 \mathrm{~cm}^{-1}$, serta gugus $-\mathrm{CH}$ aromatis pada bilangan gelombang $1451 \mathrm{~cm}^{-1}$, gugus alken tak terkonjugasi pada bilangan gelombang $1652,32 \mathrm{~cm}^{-1}$ diperkuat gugus alken pada bilangan gelombang 2922,37 $\mathrm{cm}^{-}$ 1.

\section{PEMBAHASAN}

Salah satu tumbuhan yang sering digunakan sebagai obat tradisional oleh masyarakat adalah sawo manila (Achras zapota Linn), suku Zapotaceae sebagai obat tifus, gangguan pencernaan (diare), batu ginjal dan malaria.

Kandungan kimia yang telah diketahui dalam klika sawo manila mengandung alkaloid dan tanin, sedang pada buah muda mengandung tanin, flavanoid, asam dan besi.

Ekstraksi daun sawo manila menggunakan metode maserasi karena daun sawo manila bertekstur lunak sehingga tidak merusak komponen kimia aktif dalam daun tersebut serta untuk sampel yang tidak tahan terhadap pemanasan. Metanol digunakan sebagai cairan pengekstraksi karena metanol mampu melarutkan senyawa kimia polar maupun non polar dalam simplisia.

Penelitian ini menggunakan metode pemisahan kromatografi kolom karena ekstrak n-butanol pada profil KLT dengan eluen kloroform: n-heksan (8:1) diperoleh bercak yang renggang, pengerjaannya yang mudah, juga alat yang di gunakan relatif murah dan sederhana. Proses pengelusian dilakukan menggunakan eluen yang tingkat kepolaran rendah sampai tingkat kepolaran yang tinggi agar diperoleh pemisahan yang baik yaitu bercak terpisah secara berurutan. Dari hasil kromatografi kolom didapat 7 fraksi. 
Isolasi dan identifikasi golongan komponen kimia aktif antibakteri ekstrak n-butanol sawo manila (Achras zapota LINN.) asal kota Palopo

Hasil fraksi II pada kromatografi kolom diisolasi lebih lanjut menggunakan kromatografi lapis tipis preparatif karena pada fraksi II belum didapatkan bercak tunggal karena diperoleh 4 bercak dengan jarak berjauhan, sehingga diharapkan dengan metode KLT preparatif dapat dipisahkan dengan baik, dari hasil isolasi ini didapat 4 fraksi.

Fraksi IIC dilakukan pemurnian dengan cara mencuci kristal dengan metanol absolut beberapa kali agar zat pengotor atau komponen kimia yang lain dapat dilarutkan. Metanol dipilih karena sifat metanol yang tidak melarutkan kristal yang terbentuk namun dapat melarutkan senyawa lain yang tidak diharapkan.

Uji kemurnian kristal selanjutnya adalah elusi multi eluen dan KLT dua dimensi. Elusi multi eluen menggunakan 3 variasi cairan pengelusi benzen:etil asetat (5:1), benzen:etanol (5:1) dan kloroform:nheksan (10:1). Hasil elusi nampak pada UV 254, UV 366 dan penampak bercak asam sulfat $10 \%$ diperoleh 1 bercak dengan $R f$ yang berbeda sesuai dengan tingkat kepolaran eluen. Hal ini menunjukkan dengan beberapa sistem pelarut dengan tingkat kepolaran yang beragam tetap diperoleh satu bercak tunggal. Pada uji
KLT dua dimensi menggunakan cairan pengelusi n-heksan:benzen (5:1) untuk elusi pertama dan $n$-heksan: kloroform (1:10) untuk elusi yang kedua. Hasil elusi nampak pada UV 254 nm dan UV $366 \mathrm{~nm}$ diperoleh satu bercak, ini menunjukan bahwa fraksi IIC adalah bercak tunggal.

Identifikasi fraksi IIC terhadap beberapa penampak bercak golongan komponen kimia menunjukkan warna orange-kecokelatan pada penampak bercak Dragendorf yang bertahan lama, warna cokelat pada penampak bercak Mayer dan warna kecoklatan pada penampak bercak JKJ. Hasil reaksi yang terjadi pada penampak bercak di atas pada fraksi IIC menunjukkan bahwa bercak tunggal tersebut memberikan hasil positif terhadap golongan alkaloid dan tidak memberikan hasil positif terhadap penampak bercak yang golongan kimia lain. Interprestasi data spektrum UV ultraviolet-visibel fraksi IIC memiliki satu pita pada panjang gelombang maksimum 295,5 nm, hal ini membuktikan bahwa fraksi IIC adalah senyawa tunggal dan interpretasi data spektrum infra merah menunjukkan gugus amin $(-\mathrm{N}=)$ pada bilangan gelombang $1247 \mathrm{~cm}^{-1}, 2361 \mathrm{~cm}^{-1}$ dan $1294 \mathrm{~cm}^{-1}$ diperkuat gugus amin sekunder $(-\mathrm{NH}-)$ pada bilangan 
Isolasi dan identifikasi golongan komponen kimia aktif antibakteri ekstrak n-butanol sawo manila (Achras zapota LINN.) asal kota Palopo

gelombang $3447 \mathrm{~cm}^{-1}$ dan 1294,26 $\mathrm{cm}^{-1}$, serta gugus $-\mathrm{CH}$ - aromatis pada bilangan gelombang $1451 \mathrm{~cm}^{-1}$, gugus alken tak terkonjugasi pada bilangan gelombang $1652,32 \mathrm{~cm}^{-1}$ diperkuat gugus alken pada bilangan gelombang 2922,37 $\mathrm{cm}^{-1}$. Hasil interpretasi data spektroskopi infra merah di atas mendukung hasil penampak bercak golongan komponen kimia alkaloid.

Pada KLT-Bioautografi pada pita ke-3 yaitu fraksi IIC diujikan dua bakteri uji berdasarkan hasil penelitian Irnawati Amin (2005) menunjukan bahwa pada ekstrak n-butanol menunjukan aktivitas antibakteri terhadap bakteri Escherichia coli dan Salmonella typhi. Dari hasil pengujian yang memberi aktivitas terhadap Escherichia coli tetapi tidak memberikan aktivitas terhadap Salmonella typhi, hal ini mungkin disebabkan karena adanya perbedaan senyawa aktif pada saat dalam bentuk ekstrak dengan dalam bentuk senyawa tunggal karena adanya interaksi dengan senyawa lain. Tetapi tetap memberikan aktivitas antibakteri Escherichia coli. sehingga dapat disimpulkan fraksi IIC yang aktif sebagai antibakteri terhadap Escherichia coli adalah senyawa golongan alkaloid

\section{KESIMPULAN}

Dari hasil penelitian maka dapat disimpulkan bahwa Kristal IIC adalah senyawa golongan alkaloid dengan panjang gelombang maksimum 295,5 nm, memiliki gugus amin sekunder, (-NH-), gugus amin ($\mathrm{N}=$ ), gugus $\mathrm{CH}$ aromatis, dan gugus alken tak terkonjugasi $(-\mathrm{C}=\mathrm{C}-)$ dan memberikan aktivitas antibakteri terhadap Escherichia coli .

\section{DAFTAR PUSTAKA}

1. Heyne K. Tumbuhan Berguna Indonesia II. Jakarta : Badan Litbang Departemen Kehutanan; 1987.

2. Rukmana R. Sawo. Yogyakarta: Kanisius;1997.

3. Steenis CGV. Flora Untuk Sekolah $\mathrm{Di}$ Indonesia. Terjemahan oleh Suryowinoto. M. Cetakan ke-VI, Jakarta : Penerbit PT. Pradnya Paramita;1992.

4. Wijaya KH. Tanaman Berkhasiat Obat Di Indonesia, Jilid I. Jakarta : Penerbit Pustaka Kartini;1992.

5. Dirjen POM. Sediaan Galenik, Jakarta : Departemen Kesehatan $\mathrm{Rl} ; 1986$.

6. Harbone JB. Metode Fitokimia, Penuntun Cara Modern Mengekstraksi Tumbuhan., Terjemahan Padmawinata. K., Bandung : Penerbit ITB;1987

7. Hostettman K, Hostettman M, Marston A. Cara Kromatografi Preparatif. Terjemahan 
Isolasi dan identifikasi golongan komponen kimia aktif antibakteri ekstrak n-butanol sawo manila (Achras zapota LINN.) asal kota Palopo

Padnawinata. K. Bandung : Kedua. Bandung : Penerbit Penerbit ITB; 1995.

ITB;1991

8. Adnan M. Teknik Kromatografl, Yogyakarta : Penerbit Andi;1997.

10. Noerdin D. Elusidasi Struktur Senyawa Organik, Dengan Cara Spektroskopi Ultra Lembayung Dan

9. Gritter JR, Bobbitt MJ, Schewarting EA. Pengantar Kromatografi, Terjemahan Padmawinata, Edisi Infra Merah. Bandung : Penerbit Angkasa.1985. 